\title{
Economic burden of hospitalisation for congestive heart failure among adults in the Philippines
}

\author{
Bernadette A Tumanan-Mendoza, 1,2 Victor L Mendoza, ${ }^{3,4}$ \\ April Ann A Bermudez-Delos Santos, ${ }^{1}$ Felix Eduardo R Punzalan, ${ }^{1,5}$ Noemi S Pestano, ${ }^{1}$ \\ Rudy Boy Natividad, ${ }^{1}$ Louie Alfred Shiu, ${ }^{1}$ Renelene Macabeo, ${ }^{1}$ Hilton Y Lam ${ }^{6}$
}

'Department of Internal

Medicine, Section of Cardiology, Manila Doctors Hospital, Manila, Philippines

${ }^{2}$ Department of Clinical Epidemiology, University of the Philippines Manila, College of Medicine, Manila, Philippines

${ }^{3}$ Department of Internal Medicine, Section of Cardiology, De La Salle University Medical Center, Dasmariñas, Cavite, Philippines

${ }^{4}$ Department of Physiology, De La Salle Health Sciences Institute, Dasmariñas, Cavite, Philippines

${ }^{5}$ Department of Internal Medicine, Section of Cardiology, Philippine General Hospital, Manila, Philippines

${ }^{6}$ Institute of Health Policy Development, National Institutes of Health, University of the Philippines, Manila, Philippines

\section{Correspondence to}

Dr Bernadette A TumananMendoza, Manila Doctors Hospital 667 United Nations Avenue, Ermita, Manila, Philippines; bernadette. tumanan@gmail.com

Received 13 March 2018 Revised 21 August 2018 Accepted 27 August 2018

\section{ABSTRACT}

Objectives Hospitalisation for congestive heart failure (CHF) was reported to be 1648 cases for every 100000 patient claims in 2014 in the Philippines; however, there are no data regarding its economic impact. This study determined CHF hospitalisation cost and its total economic burden. It compared the healthcare-related hospitalisation cost from the societal perspective with the payer's perspective, the Philippine Health Insurance Corporation (PhilHealth).

Methods This is a cost analysis study. Data were obtained from representative government/private hospitals and a drugstore in all regions of the country. Healthcare costs included cost of diagnostics/treatment, professional fees and other CHF-related hospital charges, while non-healthcare costs included production losses, transportation and food expenses.

Results The overall mean healthcare-related cost for CHF hospitalisation (class III) in government hospitals in the Philippines in 2014 was PHP19 340-PHP28 220 (US\$436-US\$636). In private hospitals, it was PHP28 370-PHP41 800 (US\$639-US\$941). In comparison, PhilHealth's coverage/CHF case rate payment is PHP15 700 (US\$354). The mean non-healthcare cost was PHP10 700-PHP14600 (US\$241-US\$329). Using PhilHealth's case rate payment and the prevalence of CHF hospitalisation in 2014, the total economic burden was PHP691 522200 (US\$15 574 824). Using the study results on healthcare-related cost meant that the total economic burden for CHF hospitalisation would instead be PHP851 850 000-PHP1 841563000 (US\$19 185 811-US\$41 476 644).

Conclusions The calculated healthcare-related hospitalisation cost for CHF in the Philippines in 2014 demonstrates the disparity between the actual cost and PhilHealth's coverage. This implies a need for policymakers to review its coverage to make healthcare delivery affordable.

\section{INTRODUCTION}

Congestive heart failure (CHF) is a significant health problem. Previous studies both in Western and Southeast Asian countries report a prevalence of $0.5 \%-12 \% .{ }^{1-4}$ Diagnostic procedures, long-term maintenance medications, outpatient visits and hospitalisation impact significantly on the economic status of those with heart failure. Economic productivity is likewise affected negatively as a result of the patient's reduced functional capacity. In a developing country like the Philippines, where healthcare delivery is usually obtained through out-of-pocket expenses $\left(54.2 \%\right.$ of health expenditures in 2016), ${ }^{56}$

\section{Key messages}

What is already known about this subject?

- The prevalence of hospitalisation for congestive heart failure in the Philippines was recently reported. It underscores the role of the previous study in the determination of the economic impact of hospitalisation for heart failure. Currently, Philippine Health Insurance Corporation's (PhilHealth) present case rate payment for hospitalisation for congestive heart failure is pegged at PHP15 700 (US\$354, using the average US\$ to PHP conversion rate in 2014).

What does this study add?

- This is the first study in the Philippines that estimated the hospitalisation cost using both societal and payer's perspective. It showed the disparity between PhilHealth's case rate payment and the actual hospitalisation cost based on the study. Since the study estimate was limited to the conservative cost of hospitalisation for congestive heart failure (CHF) class III, the disparity would be even greater for patients with severe CHF (class IV). Such hospitalisation cost may be catastrophic for the patient and his family.

How might this impact on clinical practice?

- The study results can be used to influence policy makers, that is, to revise the current PhilHealth case rate payment for hospitalisation for CHF. This in turn will decrease the economic burden on the part of the patient and his family. This may also lead to increase compliance to evidence-based guidelines.

its economic burden especially its hospitalisation cost cannot be overemphasised.

The Philippine Health Insurance Corporation (PhilHealth) is the government corporation mandated to oversee the National Health Insurance Program of the country. Except for few outpatient packages, PhilHealth's member benefits come in the form of hospitalisation coverage through its case rate payment schemes for specific disease conditions. ${ }^{7-9}$ This scheme makes it possible for the case rate be deducted from the patient's hospital bill on discharge. Except for patients covered by the 'No Balance Billing' Policy, ${ }^{10}$ the balance is paid by the patient and/or by other means. After a certain 


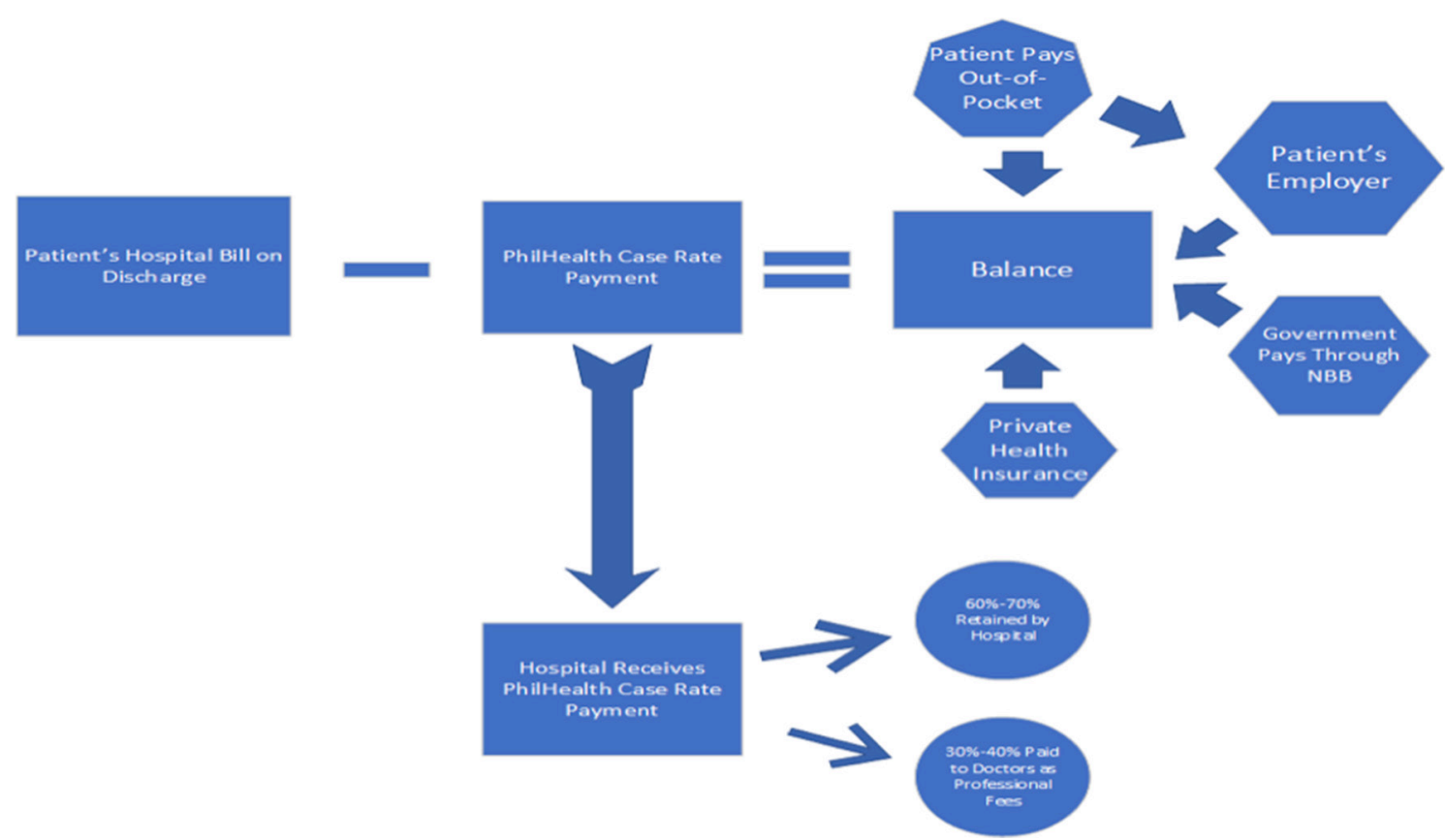

Figure 1 Flowchart illustrating settlement of a patient's hospital bill including PhilHealth coverage. PhilHealth, Philippine Health Insurance Corporation. NBB, No Balance Billing.

processing time, the hospital receives the full case rate payment from PhilHealth. ${ }^{11}$ This is illustrated in figure 1.

At present, there are no data on CHF hospitalisation cost and how Philhealth's case rate payment approximates the 'actual' hospitalisation cost. It would be important to consider how knowledge of these data can impact on the present healthcare policy, given both the patient's and country's limited resources. In view of these, this study had these objectives: the general objective was to determine the economic burden of hospitalisation for CHF in the Philippines in 2014 using the societal perspective. The specific objectives were: (1) to determine the healthcare and non-healthcare costs and the total economic burden for $\mathrm{CHF}$ hospitalisation in the Philippines and its regions in 2014 and (2) to compare the healthcare-related cost of CHF hospitalisation from the societal perspective to that of the payer's perspective (PhilHealth). The societal perspective costing include both healthcare and non-healthcare-related costs; however, the latter is excluded in the payer's perspective. In view of this, the case rate payment was compared with the healthcare-related cost portion of the societal perspective's hospitalisation cost.

\section{METHODOLOGY}

A scenario mimicking a usual patient in the Philippines with $\mathrm{CHF}$ class III from the time he enters the emergency room (ER) up to discharge from the hospital was created. This served as the basis for the cost analysis of the CHF hospitalisation in the country. This scenario was discussed and agreed on by the authors who are either cardiology consultants (five authors) or in cardiology training during the time of the study (three authors). Data on hospital charges were obtained through convenient sampling of government and private hospitals in all the 17 regions of the country (one government/private hospital for each region, total of 34 hospitals). All hospital charges related to CHF hospitalisation, starting from patient's entry to the ER up to discharge were collected. The range in the charges from lowest to highest, for example, confinement in the ward versus private room were also collected.
However, clinical data like the duration of hospitalisation and patients' mean age were obtained from the study that looked into the prevalence of CHF hospitalisation in $2014 .^{12}$

Following PhilHealth's classification, hospitals in the Philippines are categorised as primary, secondary or tertiary (level 1 or 2). Primary hospitals are incapable of providing the necessary diagnostic and treatment interventions required for patients with CHF. This necessitated data collection from secondary/tertiary hospitals. In cases of unavailability or free item/s in a particular hospital, the lowest possible costs were obtained from a government hospital or the drugstore chain of the nearby region.

It was expected that patients with CHF may have comorbidities like diabetes or some of them may have concomitant conditions like pneumonia; however, calculation of the hospitalisation costs for these other conditions/comorbidities were excluded to avoid confusion or too much variability in the computation.

Similar to previous local studies, the classification of the types of costs by Drummond et $a l^{13-15}$ was used in the determination of cost. This classification veered away from the terms direct and indirect costs to avoid confusion. The details are as follows:

\section{Cost of healthcare resources consumed}

This refers to fixed or overhead costs (eg, electricity) and variable costs (eg, supplies) for a health programme. Since the hospital charges already cover the cost of these resources, no items were included under this category to prevent double counting.

\section{Patient and family resources}

This refers to the out-of-pocket expenses shouldered by the patient and his family. This included cost of treatment, diagnostic procedures, ER charges, accommodation, professional fees (PFs), supplies and other charges related to the delivery of care. Except for the cost of medicines, the costs of all of these were obtained from the hospital charges. All of these charges (including those for medicines) are contained in the patient's hospital bill. These are summarised in table 1 . 
Table 1 Components of healthcare-related hospitalisation cost for congestive heart failure (CHF)

\begin{tabular}{|c|c|c|}
\hline Cost centre & Number (\#) & Unit cost (range) \\
\hline $\begin{array}{l}\text { Emergency room (ER) charges: consisted of charges } \\
\text { for use of oxygen } / \mathrm{O}_{2} \text { cardiac monitor, electrodes, } \\
\text { pulse oximeter in the ER; intravenous insertion and } \\
\text { ER fees. }\end{array}$ & $\begin{array}{l}\text { Number depends on the specific item, for example, cost for use } \\
\text { of } 2 \mathrm{~L} \text { per nasal cannula per hour for } \mathrm{O}_{2} \text { consumption. }\end{array}$ & $\begin{array}{l}\text { Depends on the item and specific hospital (cheaper in } \\
\text { government hospitals). }\end{array}$ \\
\hline $\begin{array}{l}\text { ER supplies: charges for use of alcohol, cotton balls, } \\
\text { needles, syringes, gloves, tape, intravenous cannula, } \\
\mathrm{O}_{2} \text { nasal prong, tape/micropore, heplock, soluset, } \\
\text { admission kit and other related items. }\end{array}$ & $\begin{array}{l}\text { Depends on the item, for example, } 1 \text { roll of tape/micropore ( } 3 \\
\mathrm{~m} \text {, with } 12 \mathrm{~mm} \times 5 \mathrm{~mm} \text { dimensions), } 1 \text { bottle of } 250 \mathrm{cc} 70 \% \\
\text { isopropyl alcohol, } 50 \text { cotton balls and so on). }\end{array}$ & Depends on the item. \\
\hline $\begin{array}{l}\text { Treatment: }{ }^{*} \text { includes both intravenous and oral } \\
\text { medications. }\end{array}$ & $\begin{array}{l}\text { Depends on type of treatment/dose (eg, dose and mode of } \\
\text { administration of diuretic on admission/day } 1 \text { is different on day } \\
2 \text { or day 3). } t\end{array}$ & Depends on the medication. \\
\hline $\begin{array}{l}\text { Other charges in the room: consisted of charges for } \\
\text { use of } \mathrm{O}_{2} \text { in the room, bedside commode, sanitiser } \\
\text { (applicable in some hospitals; some hospitals). }\end{array}$ & $\begin{array}{l}\text { For } \mathrm{O}_{2} \text { use: charge for } 2 \mathrm{~L} / \text { nasal cannula for } 20 \text { hours in the } \\
\text { room on day } 1 \text { and } 24 \text { hours on day } 2 \text {. }\end{array}$ & $\begin{array}{l}\text { Most of the hospitals charged } \mathrm{O}_{2} \text { use per hour per \# of } \\
\text { litres/nasal cannula; charges dependent also on specific } \\
\text { hospital, for example, PHP20/hour (US } \$ 0.45 / \text { hour) in } \\
\text { one hospital or PHP200/hour (US } \$ 4.50 / \text { hour) in another } \\
\text { hospital. }\end{array}$ \\
\hline Professional fees (attending physician). & $\begin{array}{l}\text { Philippine Health Insurance Corporation (PhilHealth) case rate } \\
\text { or based on room charge/day multiplied by mean duration of } \\
\text { hospitalisation. }\end{array}$ & $\begin{array}{l}\text { PhilHealth case rate=PHP4710 (US\$106), } \\
\text { or room rate (eg, PHP2500/day for confinement in private } \\
\text { room) multiplied by the mean duration of hospitalisation. }\end{array}$ \\
\hline
\end{tabular}

${ }^{*}$ Diagnostic and treatment interventions as mentioned in table 2.

tAssumptions on the dose of the drugs were as agreed on by the authors.

In terms of the variability in the cost of medicines among the hospitals included in the study, the costs of medicines were determined through their prices (both of the innovator drugs and generic equivalents) in a drugstore chain with branches in all the regions of the country. Drug prices from this drugstore give a better estimate of the out-of-pocket expenses than the international prices that previous literature recommended. ${ }^{15}$ The above determination eliminated variability in the cost brought about by the different mark-ups in the prices of medicines representing

Table 2 Class I recommendations for diagnostics and treatment recommendations for $\mathrm{CHF}^{*}$

\begin{tabular}{|c|c|}
\hline Diagnostics & Treatment \\
\hline Initial laboratory examinationst & Hypertension treatment/control. \\
\hline 12-lead ECG & Statin treatment for dyslipidaemia. \\
\hline BNP or Nt-proBNP & $\begin{array}{l}\text { ACE-I or ARB for patients post-MI or ACS } \\
\text { with low EF. }\end{array}$ \\
\hline Cardiac troponin T or I & $\begin{array}{l}\text { BB use for patients post-MI or ACS with } \\
\text { low EF. }\end{array}$ \\
\hline Chest radiograph & $\begin{array}{l}\text { Diuretic use for patients with } \\
\text { HFrEF if with fluid retention, unless } \\
\text { contraindicated. }\end{array}$ \\
\hline 2D echocardiogram with Doppler studies & $\begin{array}{l}\text { Treatment for obesity and diabetes } \\
\text { mellitus. } \neq\end{array}$ \\
\hline \multicolumn{2}{|l|}{$\begin{array}{l}\text { Repeat measurement of EF in patients } \\
\text { with previous measurement }\end{array}$} \\
\hline \multicolumn{2}{|c|}{$\begin{array}{l}\text { *Recommendations from the } 2013 \text { ACC/AHA CHF Guidelines. } \\
\text { tComplete blood count, urinalysis, blood urea nitrogen, creatinine, glucose, fasting lipid } \\
\text { profile, serum electrolytes (including } \mathrm{Ca}^{++} \text {, and } \mathrm{Mg}^{++} \text {), liver function test, and thyroid- } \\
\text { stimulating hormone. } \\
\text { ‡Cost for treatment of obesity and diabetes mellitus will not be covered in this study. } \\
\text { ACC/AHA, American College of Cardiology/American Heart Association; ACS, acute } \\
\text { coronary syndrome;ACE-I, ACE inhibitor; ARB, angiotensin- receptor blocker; BB, beta } \\
\text { blocker; BNP, brain natriuretic peptidex; CHF, congestive heart failure; EF, ejection fraction; } \\
\text { HFrEF, heart failure with reduced ejection fraction; MI, myocardial infarction; Nt-proBNP, } \\
\text { N-terminal pro-B-type-natriuretic peptidex. }\end{array}$} \\
\hline
\end{tabular}

the profit margins of the hospitals. In this way, the variance in the cost of medicine is due to the use of either innovator drug or different brand but of the same generics.

The variance in the PFs is due to the following. The lowest in the range, that is, the PhilHealth case rate $(30 \%$ of $\mathrm{CHF}$ case rate payment), is applicable for patients admitted in the wards of government hospitals. This is in compliance with the government's 'No Balance Billing' policy. ${ }^{16}$ However, for those who opted to be admitted in private rooms, PF higher than the PhilHealth case rate is allowed, whether the patients get admitted in a government or private hospital. The common practice is that the PFs are charged based on the daily costs of the rooms (room rate) and the duration of hospital day.

\section{Production losses}

Defined as 'wealth lost to society due to disease', ${ }^{17}$ this equates to the loss of income due to the patient's hospitalisation. In the Philippines, at least one companion/relative stays with the patient during the hospitalisation period, resulting to the said companion's income loss. The mean age of the patients with CHF in the study was $52.6 \pm 15$ years, with $48 \%$ of the study population in the 40-59 years age group, ${ }^{12}$ hence the following assumptions were used: (A) only the caretaker is economically productive; (B) both the caretaker and patient are economically productive; however, since the patient has $\mathrm{CHF}$, even if he improved on discharge, he might not be $100 \%$ economically productive, hence the assumption of 50\% economic productivity.

Production losses may be calculated through several techniques. This study used the method by which the Organization for Economic Cooperation and Development determines labour productivity, that is, by dividing a country's gross domestic product (GDP) by the total number of employed persons for a particular year. ${ }^{89}$ For the region's specific production losses, its GDP and number of gainfully employed persons for 2014 
were used for the specific production losses per region. There was one region whereby the number of gainfully employed persons for 2014 was not reported because of the tremendous damage brought by a typhoon during that time. In view of this, the number was obtained by averaging the reported number of gainfully employed persons the year before and after 2014 .

\section{Cost due to the consumption of other resources}

This category included the expenses for transportation and meals incurred by the patient's companion during the hospitalisation period. This consisted of the average cost (or incremental cost) of three meals and two snacks per day and a conservative estimate of the cost of commuting daily from the companion's residence to the hospital and vice versa via public transportation. In contrast with other cost items, the food and transportation estimates did not have a range of costs. Instead, the total reflected the sum of the daily estimate of the food and transportation expenses for each region.

In the Philippines, the family size is relatively large, and it is a customary practice to have home-cooked meals for the entire family in order to save on cost. The daily food for a family of $6 \pm 1$ is fixed. When one member of the family purchases food at the hospital, there is almost no change in the expenses (almost nil savings) for family meals cooked at home; however, there will be a marked increase in food expense brought about by buying meals in the hospital. Furthermore, the cost for meals and snacks purchased at the hospital used in the study was relatively conservative (real costs might be higher), thus even if we assume some savings in not eating at home, the additional cost will still be near the estimated cost used in the study.

The food costs were influenced by the locality or region where the patient was confined, that is, the expenses were incurred in the National Capital Region (NCR) or in areas outside NCR (AONCR). The costs were higher for NCR than in AONCR.

The mean duration of hospitalisation (dependent on the region where the hospital is located) was used as the multiplier whenever needed for a particular cost centre. For example, the cost of accommodations based on the specific room rate was multiplied by the mean duration of hospitalisation expressed in number of days.

The reference time period was 2014 since the data for the prevalence of CHF hospitalisation ${ }^{12}$ was for 2014. The costs were expressed in Philippine peso (PHP) and converted to US dollars (US\$) using the 2014 average conversion rate of PHP44.40 to US $\$ 1.00 .^{18}$ Adjustment to the 2014 real price was done through the consumer price indices of 2014 and 2016, the year the cost data were collected.

The treatment interventions and diagnostic procedures followed the class I recommendations of the 2013 American College of Cardiology/American Heart Association for the diagnosis and treatment of Congestive Heart Failure ${ }^{19}$ that are applicable to the local setting. These are listed in table 2.

The sensitivity analyses consisted of a one-way analysis through a tornado diagram and scenario analyses for the best and worst case scenarios. ${ }^{13}$ The best case represented the lowest possible cost while the worst case the other end of the spectrum.

The economic burden per region was estimated by multiplying the cost of hospitalisation by the number of patients hospitalised for CHF in every region. The total economic burden of CHF hospitalisation for 2014 was obtained by multiplying the overall mean cost of hospitalisation by the reported total number of CHF hospitalisation in the country. ${ }^{12}$

The summary of the assumptions is as follows:
1. The estimation of cost was for CHF class III patients. Generally, CHF class I-II patients are rarely hospitalised, while class IV/severe CHF patients might require intubation and staying in the intensive care unit (ICU). Some hospitals in the study are not equipped with ICU facilities. Limiting the cost to class III patients would simplify costing, decrease variability and avoid extrapolation of ICU costs to other hospitals. This, however, would lead to conservative estimates as the higher end in the cost spectrum was excluded.

2. Diagnostic and therapeutic interventions as listed in table 2 .

3. Types of costs included:

a. Healthcare cost: confinement in ward (government hospital), use of generic equivalents if available, PF based on PhilHealth case rate payment for CHF, lowest charge for diagnostic procedures, use of prices from drugstore chain for cost of supplies and other related items (unless the cost for other items were cheaper in government hospitals) represented the lowest in the range of the costs. Confinement in a private room (private hospital), use of innovator drugs, PF based on room rates, use of hospital charges for cost of supplies and other items represented the highest in the range of the costs.

Innovator drugs are the branded drugs that first came out in the market for a specific generic, for example, Lipitor for atorvastatin. The pharmaceutical company of the innovator drug holds the patent for that specific generic. Once a patent has expired, other pharmaceutical companies can come out with other drugs of the same generic. In the Philippines, many drugs of the same generic are also branded, hence the term 'innovator drugs' is used to differentiate these drugs from other branded drugs of the same generic.

b. Non-healthcare cost: this refers to production losses and cost of meals and transportation expenses (details given in the specific section).

4. Treatment costs of comorbidities/concomitant conditions (eg, diabetes mellitus and infections) were excluded. Likewise, the use of medical devices, for example, cardiac resynchronisation therapy was excluded since its high cost is beyond the reach of most Filipinos with heart failure. Moreover, availability of such devices is limited to very few centres. Thus, inclusion of its cost in heart failure hospitalisation in the Philippines is deemed unrealistic.

5. Adjustment of the costs/charges collected in 2016 to 2014 values (since patient confinement was in 2014). .

\section{RESULTS}

Determination of brain natriuretic peptidex of $\mathrm{N}$-terminal pro-B-type-natriuretic is included in the examinations with a class I recommendation; however, the study excluded this cost (PHP1000-PHP2800) in the calculation. This is in view of the usual practice of many Filipino clinicians of non-adherence to this guideline recommendation. This is probably due to the relatively high cost of this laboratory test and the problem in its availability. Among the 34 hospitals in this study, it was available in only four hospitals (three private and one government).

Table 3 shows the healthcare-related cost of hospitalisation for CHF in the country for 2014 expressed in Philippine peso (PHP) and US dollars (US\$) using the societal perspective. It gives the estimated lowest to the highest cost from both a government and a private hospital in the 17 regions in the country in $2014 .{ }^{20}$ The lowest hospitalisation cost was seen in a government hospital in Central Visayas, while a private hospital in this same region 


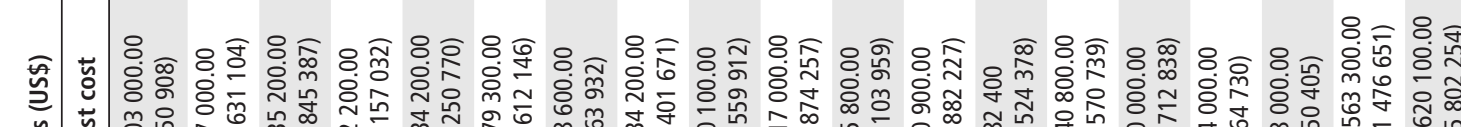

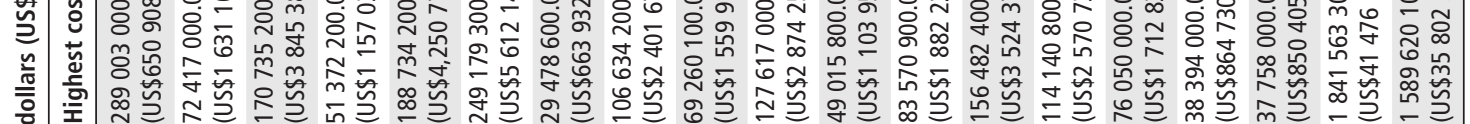

气

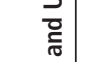

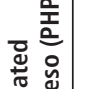

竞.

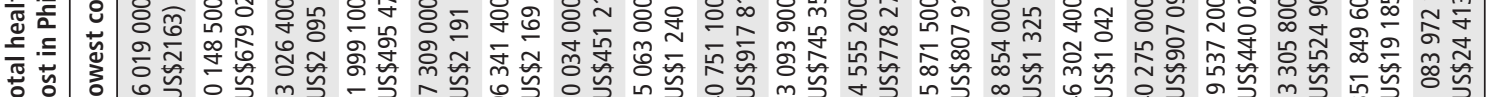

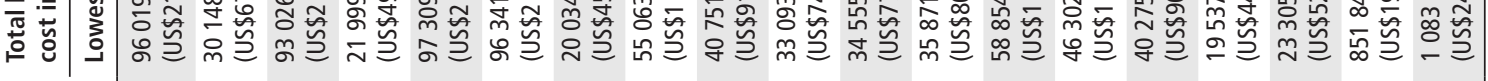
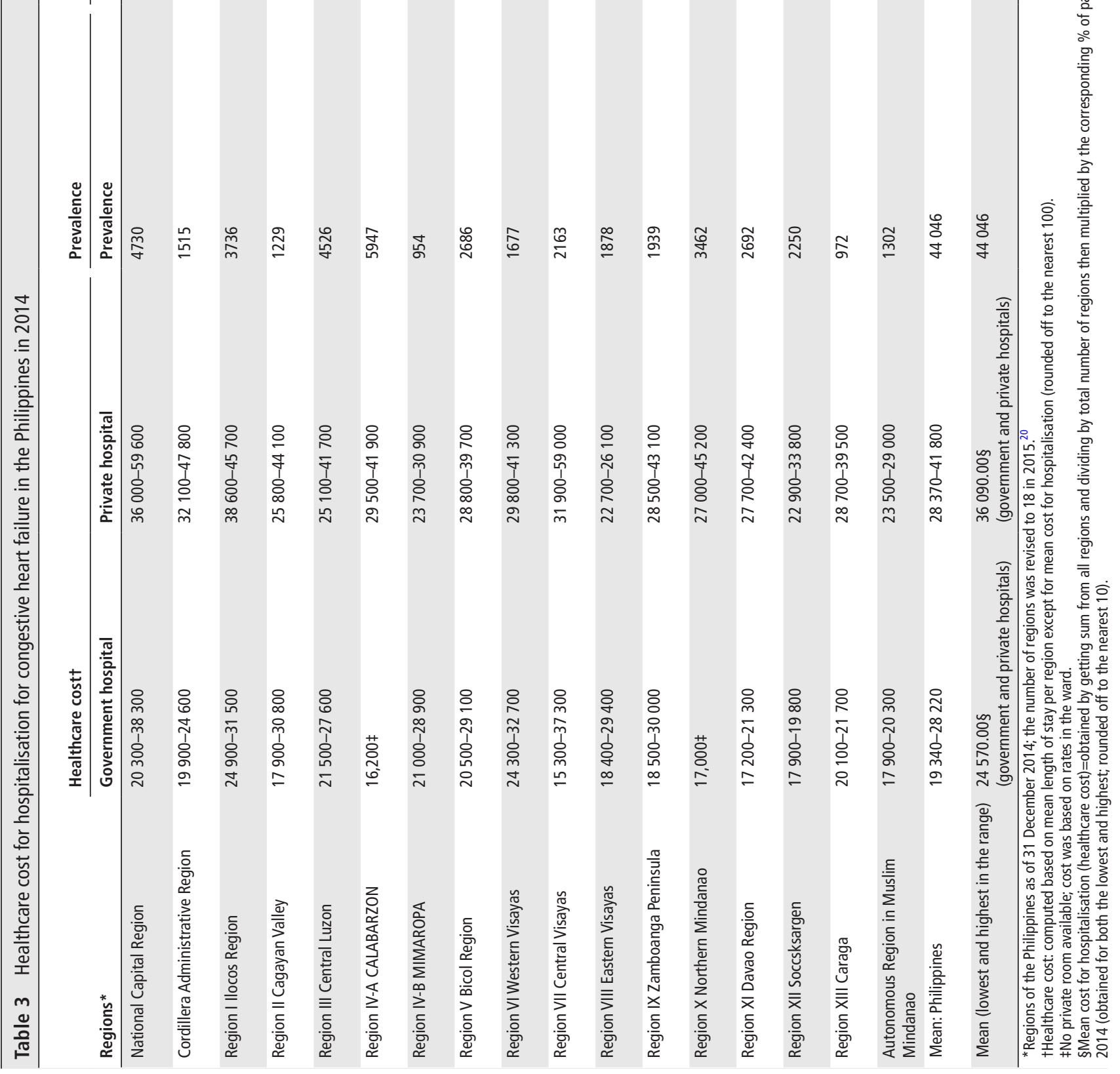
Table 4 Non-healthcare cost and total cost of hospitalisation for congestive heart failure in the Philippines in 2014

\begin{tabular}{|c|c|c|c|c|c|}
\hline \multirow[b]{2}{*}{ Regions* } & \multicolumn{3}{|c|}{$\begin{array}{l}\text { Non-healthcare cost in Philippine peso (PHP) } \\
\text { (same for government or private hospital) }\end{array}$} & \multicolumn{2}{|c|}{$\begin{array}{l}\text { Total cost of hospitalisation (healthcare+non-healthcare costs) } \\
\text { in PHPt }\end{array}$} \\
\hline & Production losses & $\begin{array}{l}\text { Other } \\
\text { resources }\end{array}$ & $\begin{array}{l}\text { Total non- } \\
\text { healthcare cost }\end{array}$ & Government hospital & Private hospital \\
\hline National Capital Region & $26970-40450$ & 5250 & $32200-45700$ & $52500-84000$ & $68200-105300$ \\
\hline Cordillera Administrative & $7120-10680$ & 3000 & $10100-13700$ & $30000-38300$ & $42200-61500$ \\
\hline Region I llocos Region & $3960-5940$ & 2750 & $6700-8700$ & $31600-40200$ & $45300-54400$ \\
\hline Region IV-A CALABARZON & $8820-13230$ & 3000 & $11800-16200$ & $28000-32400$ & $41300-58100$ \\
\hline Region IV-B MIMAROPA & $3190-4780$ & 2500 & $5700-7300$ & $26700-36200$ & 29 400-38 200 \\
\hline Region V Bicol Region & $2830-4250$ & 3250 & $6100-7500$ & $26600-36400$ & $34900-47200$ \\
\hline Region VI Western Visayas & $3930-5890$ & 3250 & $7200-9100$ & $31600-42300$ & $37000-50700$ \\
\hline Region VII Central Visayas & $7180-10770$ & 3500 & $10700-14300$ & $26000-51600$ & $42600-73300$ \\
\hline Region XII Soccsksargen & $4340-6510$ & 2750 & $7100-9300$ & $25000-29100$ & $30000-43100$ \\
\hline Region XIII Caraga & $2970-4460$ & 2750 & $5700-7200$ & $25800-28900$ & $34400-46700$ \\
\hline $\begin{array}{l}\text { Autonomous Region in } \\
\text { Muslim Mindanao }\end{array}$ & $1600-2400$ & 2000 & $3600-4400$ & $21500-24700$ & $27100-33400$ \\
\hline Overall mean: Philippines & $7600-11500$ & 3100 & $\begin{array}{l}10700-14600 \S \\
\text { (US\$241-US\%329) }\end{array}$ & $\begin{array}{l}35270-506909 \\
\text { (US\$794-US\$1142) }\end{array}$ & \\
\hline
\end{tabular}

* Regions of the Philippines as of 31 December 2014.

†Rounded-off to the nearest hundred.

‡Estimate per region (point estimates).

$\S$ Based on gross domestic product of the Philippines in 2014 and overall mean length of hospital stay.

ๆBased on overall mean cost of healthcare-related and non-healthcare-related hospitalisation cost.

had the second highest hospitalisation cost. The highest hospitalisation cost was seen in a private hospital in the NCR, though the difference between the first and second highest was only PHP600 (US\$13.51).

The overall mean cost for hospitalisation was about PHP25 000-PHP36 000 (US\$563-US\$811). This mean was obtained from the average cost from the 17 regions from each sector, that is, either government or private hospital and then multiplied by the distribution of hospitalisation $(57.9 \%$ and $42.1 \%$ were confined in private hospital and government hospitals, respectively). If the mean cost was obtained through the classification of the hospitals, the mean cost for the government hospitals was PHP19 340-PHP28 220 (US\$436-US\$636), while the range was PHP28 370-PHP41 800 (US\$639-US\$941) for the private hospitals.

Using PhilHealth's perspective, the hospitalisation cost as reflected in its case rate payment is PHP15 700 (US\$354), regardless of the severity of CHF.

Table 4 gives the non-healthcare cost for hospitalisation for $\mathrm{CHF}$ in the regions of the country. In contrast to healthcare-related cost, the non-healthcare cost was the same whether the patient was confined in a government or private hospital. This table also shows the total cost of hospitalisation, that is, sum of both healthcare and non-healthcare costs in the 17 regions and the overall mean cost. The overall mean hospitalisation cost was not simply the sum of the costs from the regions divided by the number of hospitals. Instead, it was influenced by the mean production losses, reflective of the country's 2014 GDP and the mean duration of CHF hospitalisation of all patients for 2014.

The tornado diagram (figure 2) illustrates the one-way sensitivity analysis. For example, the cost of diagnostics was changed, but the other costs were kept constant. This diagram showed that the total healthcare-related cost of hospitalisation is most sensitive to changes in the cost of diagnostic procedures while it is least sensitive to the cost of medications.

The economic burden for healthcare-related expenses for CHF hospitalisation in 2014 using the societal perspective was PHP851 850 000-1 841563000 (US\$19 185 811-US\$41 476 644). With the payer's perspective, this would be PHP691 522 000 (US\$15 574 824).

In 2014, PhilHealth reported coverage of $87 \%$ of the population. ${ }^{21}$ Extrapolating this to $100 \%$ would mean that the economic burden for healthcare-related expenses for CHF hospitalisation would be PHP1 014107 000-PHP2 192337000 or PHP823 240000 using the societal or payer's perspective, respectively.

Using the mean total hospitalisation cost seen in table 4, the total economic burden of all the patients hospitalised for CHF in 2014 would approximately be PHP1 553502 000-PHP2 232 692000 (US\$34 988 784-US\$50 285 856).

\section{DISCUSSION}

The overall mean healthcare-related hospitalisation cost for CHF in the Philippines in 2014 using the societal perspective (PHP25 000-PHP36 000) took into account all cases of hospitalisation in the country, whether the patient was confined in a government or private hospital. Disparity is seen between this amount with PhilHealth's/payer's perspective whose case rate payment for CHF hospitalisation is PHP15 700. This case rate can also be compared with the mean healthcare-related hospitalisation cost in government or private hospitals, which ranged from PHP19 340-PHP28 220 and PHP28 370-PHP41 800, respectively. One would argue that comparison should not be done with those in private hospitals since this includes the profit margins of these 


\section{Hospitalisation Cost}

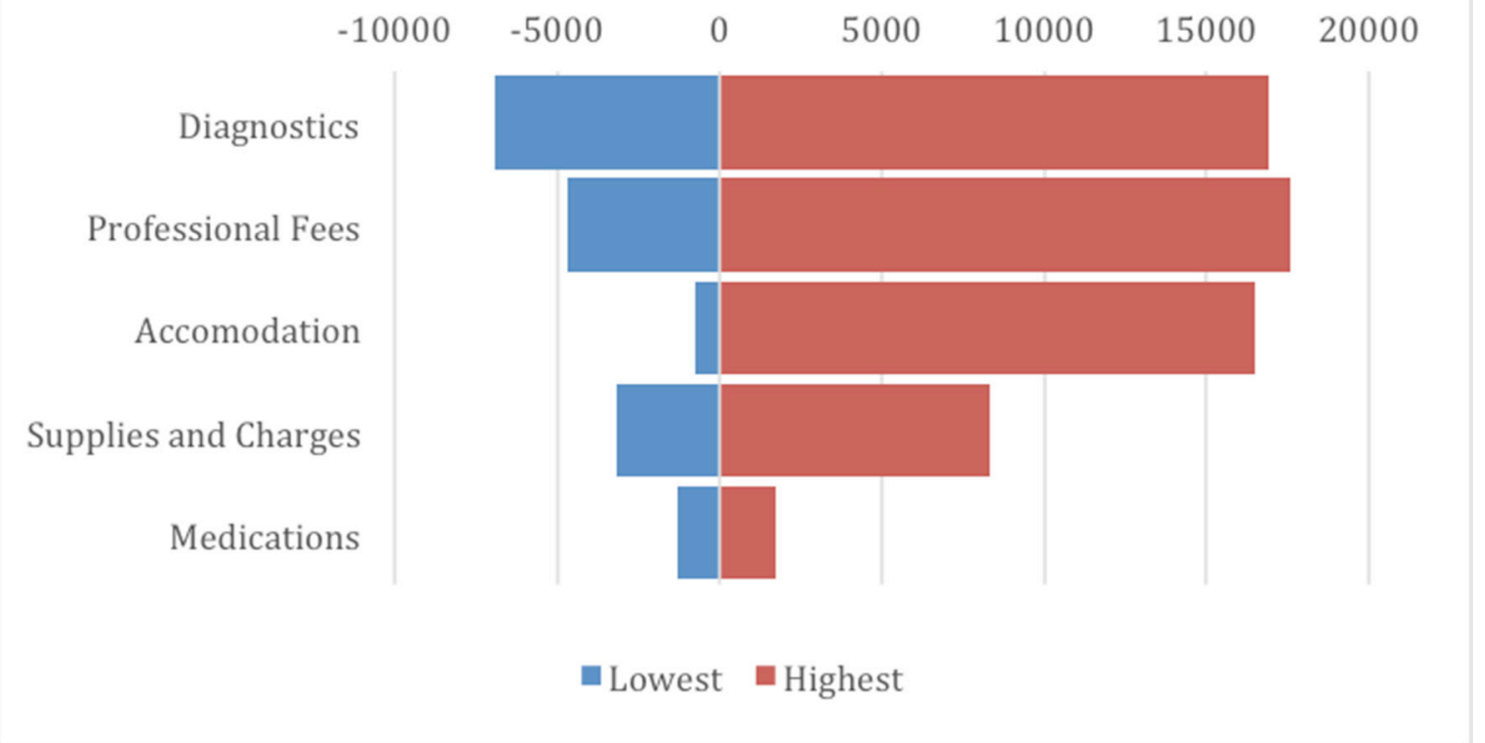

Figure 2 Tornado diagram: effects of the different components in the CHF hospitalisation cost. CHF, congestive heart failure.

facilities. It is expected that the difference between PhilHealth's case rate payment with the mean cost in government hospitals would be smaller as compared with the cost in private hospitals. There was even one government hospital whose estimated lowest hospitalisation cost was lower by a few hundred pesos than PhilHealth's case rate payment. One must be cautious in the interpretation of this data considering that this low cost was influenced by the minimal charges on many items (with some items provided for free), a feature inherent in government hospitals. For example, ward accommodation charge of PHP100/day (US\$2.25/day). This amount would not cover the expenses for the meals, nursing and other services that the hospital provides. This means that a considerable amount for the patient's hospitalisation is shouldered by the hospital. The hospital, in turn, has to source funds either from its budget provided by the local government or from charitable institutions. Private hospitals, in contrast to government hospitals, are expected to charge their patients for all the expenses incurred in the provision of the services plus a certain amount representing their profit.

For those who were hospitalised in private hospitals or those who availed of private rooms in government hospitals, the increment between the actual hospitalisation cost and PhilHealth's case rate payment are paid through: out-of-pocket expenses, private health insurance or through the patient's employer. In cases where the patient has no private medical insurance, and his/his family's resources are already insufficient, he may also seek help through charitable institutions. In a local study, it was reported that $69 \%$ and $25 \%$ of hospitalisation cost for pneumonia was paid through out-of-pocket expenses and private medical insurance, respectively. Only 6\% was paid through the patient's employer. However, part of this $6 \%$ may be considered as out-of-pocket expenses since this can be a hospitalisation loan that has to be paid through salary deductions once the patient returns to work. ${ }^{15}$

In terms of the performance measures for $\mathrm{CHF}$, these are evidence-based standards of care, focusing on specific diagnostic or therapeutic actions. ${ }^{22-24}$ There are three items in these measures that are applicable to this study. These are the measurement of left ventricular systolic function and treatment with beta blocker and ACE inhibitor or angiotensin receptor blocker. Their cost represented $12 \%-25 \%$ of the mean cost of healthcare-related hospitalisation cost. It contained the cost of the 'minimum standards' for the diagnosis and management of CHF but did not consider the costs inherent to a patient's hospitalisation like accommodations, PF and other laboratory/therapeutic interventions.

The mean non-healthcare-related cost amounted to PHP10 700-PHP14 600, representing about 30\% of the total economic burden of hospitalisation for CHF. The calculated non-healthcare costs were conservative estimates and may underestimate the actual cost for a particular patient or to society. However, it should be noted that different ways of measuring productivity losses may result in underestimation or overestimation of the actual cost to society. This is exemplified by studies, which compared the human capital approach to the friction cost method in the determination of productivity costs. The human capital approach resulted to significantly higher costs (69 times higher in one study) as compared with the friction cost method. The human capital approach based its computation on gross wages/ earnings, while the latter method rely on the time an organisation needs to restore productivity to the level it had prior to the decrease in production due to disease. ${ }^{13172526}$ However, the cost for the consumption of other resources was based on a single (also conservative, with no best and worse case scenario) daily estimate for food and transportation (public transportation) expenses per region, which may contribute to the underestimation of the actual non-healthcare cost.

Considering that the daily minimum wage of a Filipino labourer in the NCR (highest among all regions) in 2014 amounted to PHP414-PHP459, ${ }^{27}$ the effect of CHF hospitalisation on the average Filipino family could be catastrophic. In this study, 1869 (4.2\%) patients went 'home against medical advice' because the family could not afford anymore the escalating hospitalisation cost. It is also for the same reason that some patients absconded. Unfortunately, this would mean stopping treatment, and the likelihood of fatal outcome is high. For 
other patients, their hospitalisation could lead to loss of savings allotted for their children's education, even for those who earn more than the minimum wage.

It should be borne in mind that the cost estimation for this study was rather conservative. It did not include treatment cost for the most severe type, CHF class IV. These patients will possibly stay in the ICU, require the use of artificial ventilators/ prolonged hospital stay and other costly measures, resulting to increased hospitalisation cost. Moreover, the study excluded the cost of expensive cardiac implantable electronic devices for heart failure. Thus, it is expected that the study results are much lower than in countries where these expensive diagnostic and therapeutic interventions are given.

In view of the marked difference between the case rate payment and 'actual' hospitalisation cost, due consideration must be given to increasing the coverage and having at least two different case rates to reflect the severity of CHF, either class III or class IV/severe. This would be in the same way that coverage for pneumonia is differentiated into either moderate (PHP15 000) or high risk (PHP32 000). ${ }^{28}$ Increasing the case rate payments would increase access to healthcare and decrease the catastrophic effects of CHF among Filipino families and may increase treatment adherence. Moreover, increased government spending brought about by these payments will help it attain its targets for several healthcare financing indicators. To illustrate, the Department of Health included the following targets for 2014: 6.0\% for government spending on health as percentage of total government spending, $45.0 \%$ for out-of-pocket spending and $19.0 \%$ for PhilHealth spending both as percentage of total health expenditures. These were missed since the actual data for these indicators were $5.0 \%, 55.8 \%$ and $14.2 \%$, respectively. ${ }^{5}$ However, this increase in PhilHealth spending can be sourced from the new tax law. This law provides for the increase in taxes for cigarettes and sweetened beverages, which in turn will support measures to prevent and control non-communicable diseases and provide more PhilHealth benefits among other programme..$^{29}$

It is important to know the percentage of CHF class IV patients; however, the present PhilHealth reporting does not discriminate between class III and IV patients. An ongoing CHF registry being conducted by the Philippine Heart Association includes the above item in its data collection. Although this registry is limited to tertiary hospitals/centres with cardiology training programme, an approximation of the percentage of CHF Class IV patients may be extrapolated from this study. Having different case rate payments for CHF class III and IV will provide the nationwide data of these classes of CHF patients in the future.

Lastly, revising the CHF case rate payments would emphasise its clinical importance and rectify inequity in terms of coverage of some relatively benign conditions in contrast to CHF. For example, the present CHF case rate payment (PHP15 700) is much lower than those for excision of synovial cyst of the popliteal space (Baker's cyst) and correction of hallux valgus/bunion whose coverage are PHP20 980 and PHP20 980-PHP23 080, respectively. ${ }^{28}$

\section{CONCLUSIONS}

The calculated healthcare-related hospitalisation cost for CHF in the Philippines in 2014 demonstrates the disparity between the actual cost and PhilHealth's coverage. This implies a need for policymakers to review its coverage to make healthcare delivery affordable, especially for patients with CHF.
Furthermore, the huge economic burden of hospitalisation for CHF may mean loss of some opportunities for the average Filipino family.

Acknowledgements The authors would like to acknowledge the help of the following in the collection of data for the study: Jenna M Gonzalez, RN, Arthur Pitargue, Ellen Pan, Joji D Daguio, RN, Maria Olive B Mata, RN, Care Bautista, Juliet Macahilas, Jaypee Andrew Yepes, Luchi Foraleza, Annie Du Yabut, Karina Lorena, Ashley Trapela, RN, Ella Dela Pena, Dawn Aberilla, Grace Simbul and Aivy Siongco.

Contributors All authors have contributed to the protocol development. BAT-M monitored the data collection, analysed the data, prepared the draft of the paper and did revisions prior to its submission to Heart Asia. VLM contributed to the data collection, analysis of the data and revisions of the draft prior to the submission process. AAAB-dS helped in the data collection, revising the drafts and completing the requirements for the submission process. FERP reviewed the draft of the paper before submission for possible publication. NSP, RBN, LAS and RM contributed to the data collection and NSP also reviewed the draft. HYL reviewed the draft prior to the publication process. BAT-M is the guarantor. All authors have given approval to this version for publication.

Funding The paper was funded through a research service agreement from Novartis Healthcare Philippines, Inc. to De La Salle Health Sciences Institute, Dasmariñas, Cavite. The authors developed the protocol, analysed the results and wrote the paper independently of the sponsor.

Competing interests None declared.

Patient consent Not required.

Ethics approval Independent Ethics Committee, De La Salle Health Sciences Institute.

Provenance and peer review Not commissioned; externally peer reviewed.

\section{REFERENCES}

1. Roger VL. Epidemiology of heart failure. Circ Res 2013;113:646-59

2. Hung YT, Cheung NT, Ip S, et al. Epidemiology of heart failure in Hong Kong, 1997. Hong Kong Med I 2000;6:159-62.

3. Chong AY, Rajaratnam R, Hussein NR, et al. Heart failure in a multiethnic population in Kuala Lumpur, Malaysia. Eur J Heart Fail 2003;5:569-74.

4. Lam CSP. Heart failure in southeast Asia: facts and numbers. ESC Heart Fail 2015;2:46-9.

5. Philippine Statistics Authority, 2017. Each Pinoy spent 5,859 for health in 2014. https://psa.gov.ph/content/each-pinoy-spent-5859-health-2014 [accessed 10 Sep],

6. Philippine Statistics Authority, 2018. Total health expenditures grew by 10.5 per cent in 2016. https://psa.gov.ph/national-health-accounts-press-releases [accessed 3 Apr, 2018].

7. Official Gazette, 2017. PhilHealth. Available from: http://www.gov.ph/services/ philhealth-gis/ [accessed 29 Jan, 2017].

8. Philippine Health Insurance Corporation, Mandate and Functions, 2015. http://www. philhealth.gov.ph/about_us/mandate.html [accessed 8 Jul, 2015].

9. PhilHealth, 2017. Get to know your PhilHealth benefit in just one click. https://www. philhealth.gov.ph/news/2015/knowyour_benefit.html [accessed 31 Jan, 2017].

10. PhilHealth Circular No. 011-2011, 2018. New philhealth case rates for selected medical cases and surgical procedures and the no billing policy. Available from: https://www.philhealth.gov.ph/circulars/2011/circ11_2011.pdf [accessed 30 Mar].

11. PhilHealth Benefits - Case Rate Payments for Certain Medical and Surgical Cases, 2018. Available from: http://www.workingpinoy.com/2011/08/philhealth-benefitscase-rates-medical-surgical/ [accessed $30 \mathrm{Mar}, 2018]$.

12. Tumanan-Mendoza BA, Mendoza VL, Bermudez-Delos Santos AA, et al. Epidemiologic burden of hospitalisation for congestive heart failure among adults aged $\geq 19$ years in the Philippines. Heart Asia 2017;9:76-80.

13. Drummond MF, Sculpher MJ, Torrance GW. Methods for the economic evaluation of health care programmes. 3rd edn. Oxford: Oxford University Press, 2005.

14. Tumanan-Mendoza BA, Mendoza VL, Morales DD. Cost analysis for the management of acute coronary syndrome using different quality of care indicators. Acta Medica Philippina 2009;43:15-22.

15. Tumanan-Mendoza BA, Mendoza VL, Punzalan FER. Economic burden of communityacquired pneumonia among adults in the Philippines: its equity and policy implications in the case rate payments of the Philippine Health Insurance Corporation. Value Health Reg Issues 2015;6:118-25.

16. PhilHealth Circular No. 2017-0006, 2018. Strengthening the implementation of the no balance billing policy (revision 1). https://www.philhealth.gov.ph/circulars/2017/ circ2017-0006.pdf [accessed 17 Aug, 2018].

17. Koopmanschap MA, Rutten FF, van Ineveld BM, et al. The friction cost method for measuring indirect costs of disease. J Health Econ 1995;14:171-89. 
18. Pesos Per US Dollar Rate 2010-2016, 2017. http://www.bsp.gov.ph/statistics/spei_ new/tab12_pus.htm [Accessed 2 Jan, 2017].

19. Yancy CW. ACCF/AHA Guideline for the management of heart failure. Circulation 2013;128:000.

20. Creating a Negros Island Region and for Other Purposes, 2016. http://www.gov.ph/ 2015/05/29/executive-order-no-183-s-2015/ [accessed 11 Jun, 2016].

21. Philippine Health Insurance Corporation, Stats and Charts, Second Semester, 2014. http://www.philhealth.gov.ph/about_us/statsncharts/snc2014_2nd.pdf [accessed 8 Jul, 2015].

22. Bonow RO, Ganiats TG, Beam CT, et al. ACCF/AHA/AMA-PCPI 2011 performance measures for adults with heartfailure: a report of the American College of Cardiology Foundation/American Heart AssociationTask Force on performance measures and the American Medical Association-PhysicianConsortium for performance improvement. Circulation 2012;125:2382-401.

23. AHA/ACC Conference Proceedings: Measuring and Improving Quality of Care. A report from the American Heart Association/American College of Cardiology first scientific forum on assessmentof health care quality in cardiovascular disease and stroke. Circulation 2000;101:1483-93.
24. Spertus JA, Eagle KA, Krumholz HM. American College of Cardiology and American Heart Association Methodology for the selection and creation of performance measures for quantifying the quality of cardiovascular care. Circulation 2005;111:1703-12.

25. Department of Labor and Employment National Labor and Productivity Commission, 2017. Summary of daily minimum wage rates per wage order, by region non-agriculture (1989 - 2016). http://www.nwpc.dole.gov.ph/pages/ statistics/stat_wage\%20rates1989-present_non-agri.html. [accessed 26 Jan, 2017].

26. Drummond MF, Sculpher MJ, Claxton K. Methods for the economic evaluation of health care programmes. 4th edn. Oxford: Oxford University Press, 2015.

27. Drummond M, McGuire A. Economic evaluation in health care merging theory with practice. Oxford University Press: Oxford, 2001.

28. PhilHealth, 2018. Case rates search. https://crs.philhealth.gov.ph/ [accessed 17 Aug 2018].

29. Department of Health Republic of the philippines, 2018. DOH commends the passage of the TRAIN Law. https://www.doh.gov.ph/node/12254 [accessed 17 Jun]. 